\title{
Welcome to Rachel Harrison, the new Editor-in-Chief of the Software Quality Journal
}

\author{
James Bieman
}

Published online: 11 September 2008

(C) Springer Science+Business Media, LLC 2008

As the "In This Issue" indicates, starting with the next issue, Rachel Harrison will take over the Software Quality Journal. I knew of Rachel's research long before I had the opportunity to meet her at a conference. She joined the $S Q J$ Editorial Board soon after I took over as Editor-in-Chief. She has been one of the most active members of the boardshe has supervised the reviews of many papers and has insured that these papers were reviewed carefully and promptly.

Rachel is currently the Managing Director of Stratton Edge Consulting. She is also a Visiting Professor at the University of Reading and a Visiting Senior Research Fellow at The Open University. She was a Professor at the University of Reading for over six years where she served as Head of the Computer Science Department, School Director of Research, Co-Director of the Reading e-Science Centre, and Co-Director of the Informatics Research Centre. She received her Ph.D. in Computer Science from the University of Southampton, and M.Sc. in Computer Science from University College London, and an M.A. in Mathematics from the University of Oxford. She is also a Chartered Engineer. Rachel is a well-known software engineering researcher with over 90 research papers published in a wide variety of books, journals, and conferences. Her research focus has been on empirical software engineering with an emphasis on requirements, software evolution, software architecture, and software measurement. Her research has been funded by numerous funding agencies. Rachel Harrison is clearly a productive researcher, and her practical experience shows that she understands the needs of practitioners.

Rachel has taken many leadership roles in the software engineering community. She has been a program committee member for dozens of software engineering research conferences and workshops including highly regarded meetings such as ICSE, ICSM, ISESE, and Metrics. In addition to serving on the Software Quality Journal Editorial Board, she has served on the Editorial Boards of the International Journal of Cognitive Informatics, IEE Proceedings: Software, and the Journal of Software Measurement. She has been the Guest Editor for special issues of the Journal of Systems and Software and IET Software.

J. Bieman $(\bowtie)$

Computer Science Department, Colorado State University, Fort Collins, CO, USA

e-mail: bieman@cs.colostate.edu 
I am confident that the Software Quality Journal will be in good hands under Rachel Harrison's leadership. I expect that she plans to make some changes and improvements after she takes over. 